\title{
Knowledge spillovers, transboundary pollution, and growth
}

\author{
By Nedim M. Alemdar* and Süheyla Özyildirim† \\ * Department of Economics, Bilkent University, 06533 Ankara, Turkey \\ $\uparrow$ Department of Management, Bilkent University, 06533 Ankara, Turkey; email: \\ suheyla@bilkent.edu.tr
}

\begin{abstract}
Trade in natural resources is construed as a dynamic game between North and South. Policies that promote growth in the North also cause knowledge spillovers and transboundary pollution in the South. Cooperative and noncooperative Nash equilibria of this strategic trade game are simulated under various scenarios by parallel genetic algorithms to highlight the distortions in the growth/pollution trade-off. Absent cooperation, both regions benefit when North simultaneously cuts waste and increases knowledge spillovers, impelling South to reciprocate by lower resource prices.
\end{abstract}

\section{Introduction}

Natural resources comprise an important share of world trade. While the industrialized North depends on them as indispensable factors of production, for many Southern economies they are the main source of export revenues. Also, a large scale exploitation of nature as an industrial resource base can cause significant environmental damage that may long persist, or may even be irreversible. Consequently, there exists a vast literature on natural resource economics. In this paper, we emphasize the strategic nature of trade in natural resources as a dynamic game between North and South. ${ }^{1}$ As common in North/South trade models, North is specialized in the production of manufactured goods that are consumed in both regions but accumulated only in the North, and South is the sole supplier of natural resources. ${ }^{2}$

A number of studies have adopted the North/South framework to study environmental issues related to trade. In Copeland and Taylor (1994), given the relative deficiency of human capital initially, South specializes in low-skill/ pollution-intensive goods so that trade leads to a rising level of pollution along with income. Chichilnisky $(1993,1994)$ points to ill-defined property rights over

\footnotetext{
${ }^{1}$ See Dasgupta (1982) for interesting discussions of some of the trade-cum-environment issues. For dynamic game models in environmental economics, see among others, Levhari and Mirman (1980), Dockner and Van Long (1993), Van der Ploeg and De Zeeuw (1992, 1994).

${ }^{2}$ In spirit, the model is similar to Galor (1986). It is extended, however, to study issues related not only to trade and growth, but to the environment as well.
} 
Southern resources leading to overexploitation and excessive pollution. A Southern resource monopoly is efficient since it will reduce pollution, but is also undesired as Northern growth will be diminished. In Alemdar and Özyildirim (1998), the deleterious effect of a resource monopoly on growth is mitigated when knowledge accumulation is attended with spillovers to the South.

This paper addresses three specific issues that are important and yet underplayed in the previous literature on trade, growth and the environment. First, pollution can accumulate over time to inflict lasting damage on the Southern environment; second, as a by-product of Northern production of manufactured goods some waste material may be dumped in the South causing transboundary pollution; ${ }^{3}$ third, there can be multiple resource producers, each internalizing only the pollution from resource extraction in its own locale, thus creating an additional distortion. The simultaneous presence of these externalities adds new dimensions to the strategic North/South trade game.

Unfortunately, however, the above externalities interact in a highly nonlinear dynamic terrain so that distortions so created can not be easily disentangled by analytical tools. Another contribution of our paper is to demonstrate that genetic algorithms can successfully tackle these complex dynamic game problems with power and numerical efficacy. To shed light on the growth/pollution dynamics, we use parallel genetic algorithms to approximate the model under various sets of parameters.

Our numerical simulations indicate, for instance, that the presence of transboundary pollution significantly alters the way knowledge spillovers interact with a resource monopoly. When transboundary pollution is absent, monopolistic resource prices stifle Northern growth to the extent that underinvestment and underpollution become ever more severe with larger knowledge spillovers. However, if transboundary pollution is present, larger knowledge spillovers constrict Southern monopoly pricing thereby accelerating Northern growth, and lead ultimately to overinvestment and overpollution. Moreover, these effects are more pronounced when pollution is more persistent in the South.

Still more serious inefficiencies arise when multiple producers extract resources in the South. The strategic rivalry between two resource producers in the South, for example, brings about inefficiently low resource prices. Since each producer sets its own path of resource extraction independently, and because neither cares about pollution in the other, they are led to extract resources at inefficiently high rates. North reaps the benefits from the rivalry as improvements in its terms of trade to increase production and consumption of the manufactured goods. Faced with lower resource prices, and given its lack of care for the pollution in neither country, North not only overproduces, but also employs inefficiently high resource/knowledge mix to cause excessive pollution in the South.

${ }^{3}$ Sachs et al. (1998), for instance, provide numerous examples showing how toxic waste material is dumped in the South. 
Our experiments demonstrate that the efficiency gains from cooperation can be substantial; if not between North and South, at least between Southern resource producers. However, cooperation in the international arena may be elusive for reasons all too well known. Nonetheless, even in the absence of cooperation, there can be material welfare gains to both regions if the manufacturing activities in the North generate less waste and more knowledge spillovers, thereby impelling South to lower its resource prices.

In the next section, we outline the North/South trade model wherein growth patterns are compounded with various externalities. Section 3 discusses the parallel genetic game algorithms that approximate the model under cooperative and noncooperative modes of behavior. We discuss our numerical results in Section 4. Section 5 concludes with further remarks and possible extensions.

\section{The model}

\subsection{Non-cooperative North/South trade}

Two regions, North and South, comprise the global economy. North employs a concave production technology, $Y=F(K, R, u)$, to produce manufactured goods to consume and invest in the North, and to export to the South at a world price of unity. The broad capital, $K$, measures the current state of the technical knowledge in the North, $R=\sum_{i=1}^{m} R_{i}$ is the total undifferentiated raw material imported from the Southern producers, $I=1, \ldots, m$, and $u$ stands for all other determinants of output.

The Northern stock of knowledge evolves according to

$$
\dot{K}_{t}=Y_{t}-p_{t} R_{t}-\delta K_{t}-C_{t}^{N}
$$

where $p_{t}$ is the relative market price of resources (Southern terms of trade), $0<\delta<1$ is the rate of depreciation of the broad capital. Henceforth, a dot over a variable denotes its time derivative while superscripts $\mathrm{N}$ and $\mathrm{S}$ stand for North and South, respectively. Note from eq. (1) that the pace of knowledge accumulation in the North is affected by both regions' desired consumption profiles. South consumes all proceeds from the resource sale; nevertheless, it still exercises a control over the Northern growth by its choice of terms of trade.

North's production and consumption plans maximize the utility functional

$$
J^{N}=\max _{C_{t}^{N}, R_{t}} \int_{0}^{\infty} \mathrm{e}^{-\rho_{N} t} U\left(C_{t}^{N}\right) \mathrm{d} t, \quad 0<\rho_{N}<1
$$

and also obey eq. (1), $K(0)=K_{0}$, and $C_{t}^{N} \geqslant 0$ for all $t$. The momentary utility function, $U\left(C_{t}^{N}\right)$, is strictly concave, and $\rho_{N}$ denotes the rate of pure time preference.

In extracting resources, producers in the South use a common constant returns to scale production function, $R_{i t}=r L_{i t}, r>0$ and are assumed to be unconstrained by labor availability, $L_{i t}$. Resource extraction damages the local environment to which North also adds (with no consequence to its own environment) by disposing 
the waste from its manufacturing activities. ${ }^{4}$ The local environmental damage, however, is partially curbed by the unintended diffusion of knowledge from the North.

The stock of pollution in the $i$ th locale, $P_{i}$, builds up according to

$$
\dot{P}_{i t}=\frac{1}{\gamma} \frac{R_{i t}^{\gamma}}{K_{t}^{\phi}}+\varphi_{i} Y_{t}-\Psi P_{i t}
$$

where $\gamma>0,0<\phi, \Psi<1$, are common parameters across locales. The exponential order of environmental damage due to extraction is measured by, and $\phi$ is a knowledge diffusion parameter signifying the degree of applicability of knowledge to pollution reduction. The extent of transboundary pollution is parameterized by $\varphi_{i}$, and $\Psi$ indicates the rate at which pollution decays naturally.

We assume pollution to be only locally internalized in the South. Thus, given the Northern demand for resources, Southern producers choose their production plans to maximize their respective lifetime welfare

$$
J_{i}^{S}=\max _{R_{i t}} \int_{0}^{\infty} \mathrm{e}^{-\rho_{S} t} U\left(C_{i t}^{S}, P_{i t}\right) \mathrm{d} t \quad 0<\rho_{S}<1
$$

subject to $P_{i}(0)=P_{i 0}, K(0)=K_{0}, C_{i t}^{S} \geqslant 0$ for all $t$, eqs (1), (2) and

$$
\begin{aligned}
C_{i t}^{S} & =p_{i t} R_{i t}, \\
p_{t} & =\frac{\partial F\left(K_{t}, R_{t}, u\right)}{\partial R_{i t}}
\end{aligned}
$$

The pure rate of time preference, $\rho_{s}$, is assumed to be common in the South. Instantaneous utility is separable in consumption $C_{i t}^{S}$, and pollution $P_{i t}$ so that $U\left(C_{i t}^{S}, P_{i t}\right)=U\left(C_{i t}^{S}\right)-D\left(P_{i t}\right)$. The momentary utility from consumption, $U\left(C_{i t}^{S}\right)$, is strictly concave, and $D\left(P_{i t}\right)$ is increasing in $P_{i t}$.

\subsection{Cooperative North/South trade}

In designing cooperative pricing and growth strategies, North and South ought to agree in advance as to how they will share the potential gains. The distributive outcome depends on the weights, $\omega_{i} s$, attached to each regional welfare. In turn, $\omega i_{s}$, are determined by the relative power of the parties in a bargaining framework. This is outside the scope of our inquiry. Instead, to enable welfare comparisons across scenarios, we assume equal weights.

In a more general setting, given a set of weights, Pareto-efficient solutions satisfy

$$
J=\max _{C_{t}^{N}, p_{t}, R_{1 t}, \ldots, R_{m t}} \int_{0}^{\infty}\left\{\omega_{\mathrm{o}} \mathrm{e}^{-\rho_{\mathrm{N}} t} U\left(C_{t}^{N}\right)+\sum_{i=1}^{m} \omega_{i} \mathrm{e}^{-\rho_{s} t}\left[U\left(C_{i t}^{S}\right)-D\left(P_{i t}\right)\right]\right\} \mathrm{d} t,
$$

subject to

${ }^{4}$ This assumption is for the sake of computational convenience rather than realism. We are not downplaying the significance of pollution in the Northern hemisphere, but expanding the model to admit it would significantly increase our computational cost. 


$$
\begin{aligned}
\dot{K}_{t} & =Y_{t}-p_{t} R_{t}-\delta K_{t}-C_{t}^{N}, \\
\dot{P}_{i t} & =\frac{1}{\gamma} \frac{R_{i t}^{\gamma}}{K_{t}^{\phi}}+\varphi_{i} Y_{t}-\Psi P_{i t}, \\
C_{i t}^{S} & =p_{t} R_{i t},
\end{aligned}
$$

given $K_{0}, P_{i 0}$, for all $t, C_{t}^{N}$ and $C_{i t}^{S} \geqslant 0$, and $\sum_{i=0}^{m} \omega_{i}=1$.

A cooperation between North and South, or a coordination amongst Southern producers, needs to be supported by binding agreements. In the absence of a global institution with a mandate to enforce such decisions precommitment to cooperation is not credible. Nonetheless, cooperative solutions are still of interest in so far as they indicate welfare losses that are likely to ensue given a lack of commitment.

\section{Solution methods}

\subsection{Outline of a simple genetic algorithm}

A genetic algorithm is an iterative search heuristic based on the mechanics of natural evolution. At any generation, say $z$, the algorithm maintains a constantsize population, $\operatorname{Pop}(z)$, of candidate solutions to breed yet better solutions. By iterating on a population of well-adopted sample points rather than a single point, the probability of getting stuck at a local optimum is reduced. The GA operators are simple enough, involving no more than random number generation, string copying and partial string exchanging; yet, the resulting search performance is impressive (Goldberg, 1989).

The first step of optimization with a GA is to code the parameter set of the optimization problem as a finite-length string, usually over the binary alphabet $(\{0,1\})$. The initial population, $\operatorname{Pop}(0)$, is generally random.

Next, given an objective function, each string is evaluated by computing its performance relative to the population, namely, its fitness score. Based on the fitness scores, the individuals in $\operatorname{Pop}(z-1)$ are copied into $\operatorname{Pop}(z)$ by a randomized selection procedure. The probability of a certain schemata, a given binary configuration, in $\operatorname{Pop}(z-1)$ being present in $\operatorname{Pop}(z)$ is proportional to that schemata's fitness score in $\operatorname{Pop}(z-1)$. By selecting structures for reproduction in such a way that the number of offspring of a given structure is proportional to that structure's performance (relative to the population), GA achieves the important property of inherent parallelism: the number of structures that contain any given schemata, changes at a rate roughly proportional to the observed average performance of all structures that contain the given schemata. This operation is an artificial version of natural selection, a Darwinian survival of the fittest among individuals. GA searches the space of binary combinations by generating and testing points in the space of structures. Since the latter space is exponentially smaller than the former, a GA is a highly efficient search procedure (Holland, 1975). 
In order to breed fitter individuals (explore other points in the search space), some variation is introduced into the new population by means of genetic recombination operators without disrupting the selection process. Crossover is the primary recombination operator in generating new populations. Crossover recombines two binary strings at a random point by exchanging the segments to the right of this point. ${ }^{5}$ Thus crossover provides for further exploration within the search space. The secondary search operator, mutation, also introduces diversity in the population by randomly changing 1's or 0's of the structure at particular locations.

Finally, the evolution terminates either after a specified number of generations, or when certain terminal conditions are fulfilled. To be assured of convergence, populations may evolve for a large number of generations. Alternatively, one can gradually increase the number of generations until no further improvements in the performance is observed.

The general outline of a GA is:

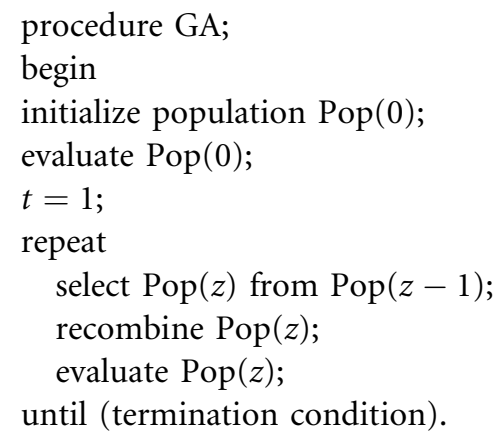

\subsection{Genetic algorithms for open-loop Nash equilibria}

An open-loop Nash equilibrium of an $n$-person differential game requires $n$ optimal control problems be simultaneously solved (Başar and Olsder, 1982). Because of the couplings between optimal decisions, generally, solving for Nash equilibria pose both analytical and numerical challenges. Our solution strategy exploits both the optimizing and the learning power of genetic algorithms. Genetic algorithms are intrinsically highly parallel mathematical structures amenable to optimization of highly complex control systems independently and simultaneously. We implement genetic algorithms in parallel, each one representing a player, to approximate the Nash equilibria in the dynamic North/South trade game where externalities further complicate the couplings.

In our genetic game algorithm, $n$ artificially intelligent players, GAs, update their strategies using an intermediary (computer shared memory) to facilitate the

\footnotetext{
${ }^{5}$ For instance, if $x_{1}=100: 01010$ and $x_{2}=010: 10100$ are two structures with the crossover point as indicated, the crossed-over structures will be $y_{1}=100: 10100$ and $y_{2}=010: 01010$. Note that in real numbers $x_{1}=138, x_{2}=84, y_{1}=148$, and $y_{2}=74$.
} 
exchange of best-to-date responses. In making decisions, each player's expectations as to what the other players will do are shaped by the information received from the shared memory in each iteration. The 'fictive' player, has no decisive role here but to pass the best-to-date (fittest) strategies in each iteration to the requesting parties synchronously.

Figure 1 shows the general outline of our genetic game algorithm tailored to a two-region, three-player dynamic trade game. In each step, $n(=3)$ genetic algorithms are involved. In order to reduce the time complexity, all three evolve for one generation while continuously sharing their respective best responses. The 'synchronize' statement is a protocol amongst GAs whereby each player waits until all players update their information before proceeding with a new search for a better strategy. This approach reduces time complexity while at the same time ensuring the convergence to a Nash equilibrium.

In the trade game, the Northern GA searches for fitter investment strategies by evolving the $k$-sized population of candidate solutions, $\left\{K_{t}^{1}, \ldots, K_{t}^{k}\right\}_{t=1}^{T}$. In each generation, the Northern GA evaluates the performances, $J^{N}\left(K_{t}^{l}, p_{t 1}^{b}, p_{t 2}^{b}\right)$ for all $l=1.2, \ldots, k$ where $p_{t 1}^{b}$ and $p_{t 2}^{b}$ are the best-to-date price vectors of the two Southern producers. Subsequently, based on these evaluations, a new Northern

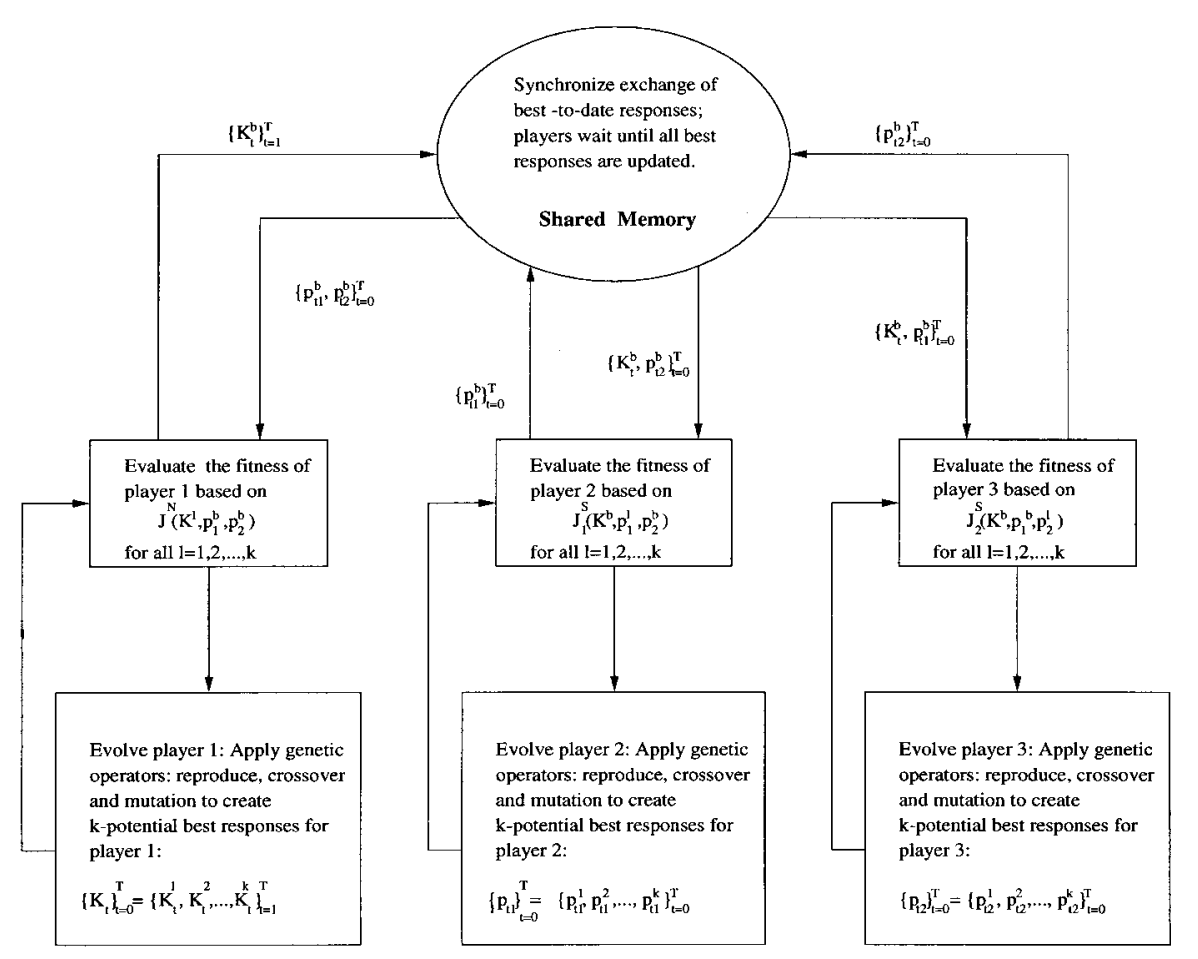

Fig. 1. Genetic algorithm for the North/South trade game 
population is selected, and the best individual is sent to the shared memory. Selection of string $l$ depends on its fitness score, or more precisely the probability

$$
\operatorname{prob}_{l}^{N}=\frac{J^{N}\left(K_{t}^{l}, p_{t 1}^{b}, p_{t 2}^{b}\right)}{\sum_{l=1}^{k} J^{N}\left(K_{t}^{l}, p_{t 1}^{b}, p_{t 2}^{b}\right)} \quad \text { for all } l
$$

Then, genetic operators are applied to the selected individuals to form a new generation.

The Southern producer GAs, on the other hand, search for fitter pricing strategies. Each maintains a $k$-sized population of respective prices, $\left\{p_{t i}^{1}, \ldots, p_{t i}^{k}\right\}_{t=0}^{T}$, for $i=1,2$. Given the best-to-date strategies, $K_{t}^{b}, p_{t 1}^{b}$, and $p_{t 2}^{b}$, the GAs evaluate respective string performances $J_{1}^{S}\left(K_{t}^{b}, p_{t 1}^{l}, p_{t 2}^{b}\right)$, and $J_{2}^{S}\left(K_{t}^{b}, p_{t 1}^{b}, p_{t 2}^{l}\right)$, for all $l$ and copy the best individuals to the shared memory. Next, for each individual $l$, the fitness score is computed as

$$
\operatorname{prob}_{1 l}^{S}=\frac{J_{1}^{S}\left(K_{t}^{b}, p_{t 1}^{l}, p_{t 2}^{b}\right)}{\sum_{l=1}^{k} J_{1}^{S}\left(K_{t}^{b}, p_{t 1}^{l}, p_{t 2}^{b}\right)} \quad \text { and } \quad \operatorname{prob}_{2 l}^{S}=\frac{J_{2}^{S}\left(K_{t}^{b}, p_{t 1}^{b}, p_{t 2}^{l}\right)}{\sum_{l=1}^{k} J_{2}^{S}\left(K_{t}^{l}, p_{t 1}^{b}, p_{t 2}^{l}\right)}
$$

Again, individuals are selected in accordance with their fitness scores, and genetic operators are used to form fitter populations.

\subsection{Genetic algorithms for cooperative games}

In cooperative games, the strategic rivalry that exists in noncooperative games is eliminated by an arbitration amongst players whereby a total welfare as some weighted sum of each player's respective welfare is maximized. Thus, solving for an equilibrium of a cooperative game is essentially equivalent to a solution of a typical optimal control problem. Conventional GA methods (see Krishnakumar and Goldberg ,1992) can be readily adopted. If choices involve some (in)equality constraints, and if direct substitution is available, then the objective function can be appropriately transformed at the outset. Otherwise, a common practice is to penalize constraint violations by appropriate penalty functions.

For $n$ control variables, $T$ periods, and $k$ potential solutions, a GA performs the following steps to optimize a control problem: (i) randomly generate an initial potential solution set, (ii) evaluate the fitness value for a solution set of $n T k$, (iii) apply selection, crossover, and mutation operations to each set of solutions to reproduce a new population, (iv) repeat steps (i), (ii), and (iii) until computation is terminated according to a convergence criterion, (v) choose the solution set $n T$ based on the best fitness value from the current generations as the optimal solution set. 


\section{Numerical experiments}

For numerical approximation, the model is reformulated in discrete-time using the method suggested by Mercenier and Michel (1994) which ensures that the continuous model and its discrete analog have the same steady state. ${ }^{6}$

For both regions, the momentary utility from consumption is assumed to be

$$
U\left(C_{t}\right)=\frac{C_{t}^{1-\sigma}}{1-\sigma} \quad \text { for } \quad \sigma>0, \sigma \neq 1
$$

while the Southerners' instantaneous disutility from pollution is

$$
D\left(P_{i t}\right)=\mu P_{i t}
$$

where $\mu>0$ converts pollution to utility. The manufactured goods are produced by a Cobb-Douglas technology, $Y_{t}=a K_{t}^{\alpha} R_{t}^{\beta}$ where $\alpha+\beta<1, a>0$, and, all uncounted inputs, $u$, are normalized to one for simplicity.

For the benchmark case, we assume the following set of parameters: $\alpha=0.8$, $\beta=0.15, \quad \gamma=2, \quad a=1, \quad r=1, \quad \mu=1 e-07, \quad \sigma=1.5, \quad \delta=0.08, \quad \rho_{N}=0.02$, $\rho_{S}=0.02, \omega_{0}=0.50, \varphi=0.01, \Psi=0.05, \phi=0.25$. These parameter values are assumed for the sake of illustration, however, they are not totally arbitrary. The value of $\mu$ is so chosen to conform with the assumed utility function.

When South is a monopoly, two separate GAs interactively update their best-todate strategies to approximate the Nash equilibrium for each set of parameters. When South is a resource duopoly, then three independent GAs search the Nash equilibrium. In the time-aggregated model, we assume 15 periods with a dense equally spaced gridding, $\Delta_{h}=0,1, \ldots, 15$ of the time horizon of $150(=T)$, which is sufficient to capture the convergence over time.

In evolving the players' best-to-date responses, the genetic operators in the public domain GENESIS package are used. ${ }^{7}$ We adopt a crossover rate of 0.60 and a mutation rate of 0.001 as suggested by Grefenstette (1986) after numerous testing on various optimization experiments. A typical run is set to evolve a population size of 50 for 240,000 generations though, perhaps, a smaller number of generations would have also sufficed to ensure convergence. From the results of the experiments in this paper, the convergence of the algorithm is evident.

In the game algorithm, we employ an 'elitist' selection strategy to retain the best performing strategies in each population of survivors. This is a natural selection rule in a noncooperative game as the evolution of Nash strategies requires that the best responses be mutually exchanged. Moreover, if it were not for the elitist selection, the fittest structures might have become extinct, preventing convergence altogether.

\footnotetext{
${ }^{6}$ See Appendix 1 for details.

${ }^{7}$ For the details of genetic operators in GENESIS, see the user's guide (Grefenstette, 1990).
} 


\subsection{Results}

In the North/South trade model, the extent of knowledge spillovers, the transboundary waste, and the permanence of pollution are parametrized by $\phi, \varphi, \Psi$, respectively, and are operative simultaneously. In order to discern how equilibrium paths are affected by these parameters, we experiment with the model under different values of $\phi, \varphi, \Psi$. Further, the equilibrium of the game is also sensitive to the market structure in the South. So, we run the benchmark experiment under a Southern duopoly as well. Tables A.1 to A.7 in Appendix 2 summarize our numerical findings.

Recall that North internalizes neither the benefits of knowledge spillovers, nor the harm its manufacturing activities inflict upon the Southern environment. As such, while the former will show up as a diminished incentive to invest, the latter will manifest as a tendency to overproduce and overinvest relative to the globally efficient paths. Also, South's market power, as reflected in its terms of trade, will determine both the long-run desired knowledge stock and the speed with which North will invest in knowledge. Moreover, if the pollution is of an enduring nature, South's welfare loss will be amplified due to a Northern noncooperation. Thus, ultimately, the deviations from the efficient paths are largely dependent on the relative magnitudes of $\phi, \varphi, \Psi$ and the extent of the Southern market power.

For example, consider an increase in waste per output, $\varphi$. Remember that the production of the manufactured goods is knowledge intensive so that resources create less waste at the margin. Thus, global efficiency demands less manufactured goods be produced with higher $R / K$ ratios (Fig. 2a). Also, due to the increased transboundary waste and lower production levels, pollution per output rises (Fig. 2c). Moreover, efficient resource prices first rise sharply to slow down growth, but then taper off to facilitate higher $R / K$ ratios in the long-run (see Table A.1-A.3).

In a noncooperative setting, transboundary waste acts as a counterbalance to monopoly prices and knowledge spillovers. When it is relatively low, production and pollution are below the efficient levels. As it increases, the Northern production falls, but not as much for North does not internalize the higher waste from its manufacturing activities. Indeed, when waste is large enough, $\varphi=0.15$, then knowledge is overaccumulated in the North (see Table A.3).

As for the transient adjustments, by and large, they are similar, and yet more sluggish than the efficient paths. Early in the growth phase when inefficiencies are most at work, pollution/output ratios rise, and then slowly approach the steady state (Fig. 2d). Also, note that $R / K$ ratios are inefficiently low, because monopoly prices are inefficiently high, and since North pays no heed to the fact that knowledge incrementally generates more waste than resources. In fact, the higher the waste rises, the further the $R / K$ ratios dip (Fig. $2 \mathrm{~b}$ ).

Next, suppose that knowledge diffusion becomes stronger, reducing the damage from resource extraction. In order to restore the world pollution to efficient levels, all else being the same, the production of manufactured goods, and consequently, 

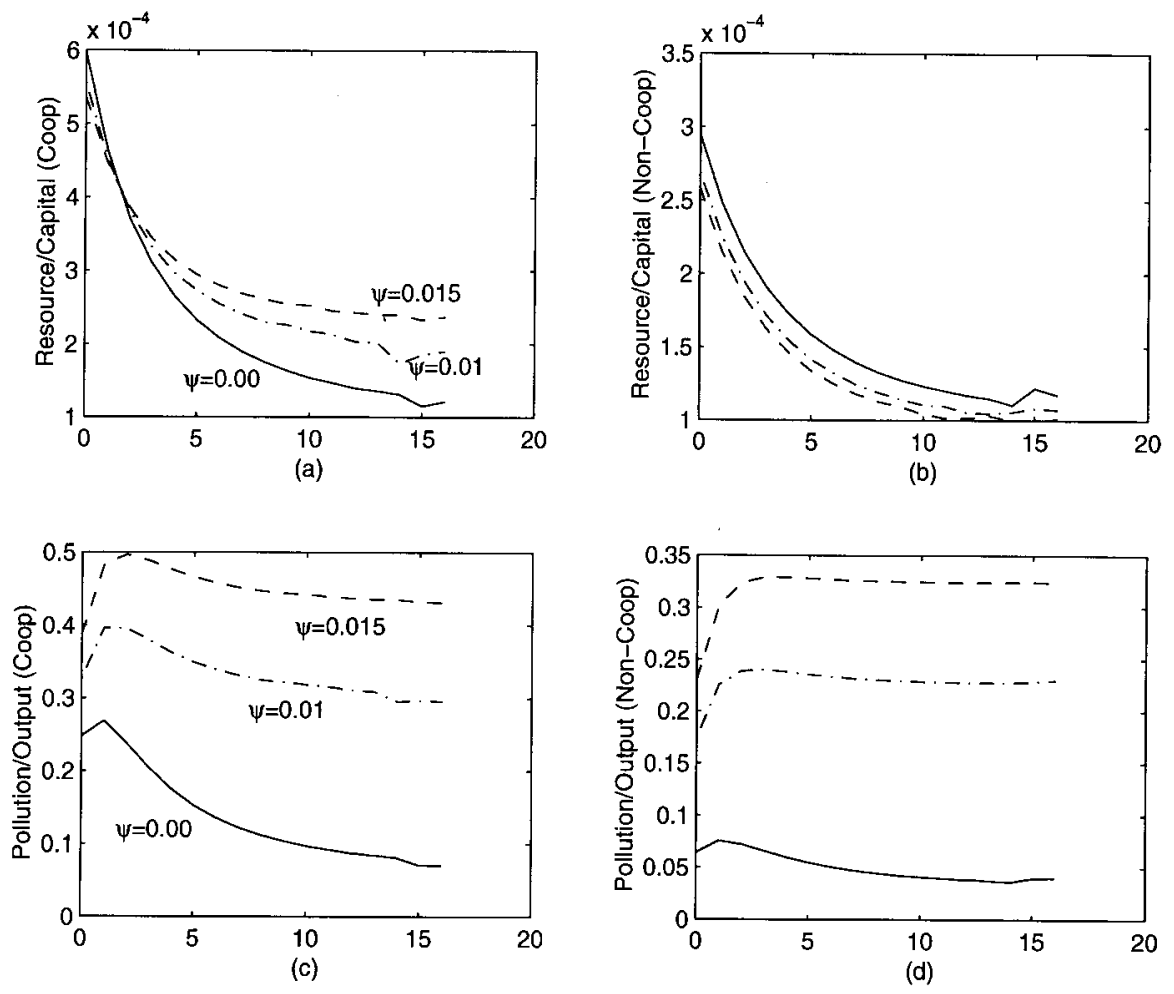

Fig. 2. Waste and trade

transboundary waste must increase. However, output expands more than pollution leading to smaller pollution/output ratios (see Fig. 3c). Since the marginal contribution of resources to waste is relatively less, efficient $R / K$ ratios also rise (see Fig. 3a). Efficient resource prices drop so as to enable higher $R / K$ ratios and also to fuel growth (see Table A.2 and Table A.4).

Turning to noncooperative paths, we note that when Northern externalities are relatively minor, production and pollution are inefficiently low, thanks to the Southern resource monopoly. A sufficiently large knowledge spillover rate, $\phi=0.50$, however, when combined with some transboundary waste, $\varphi=0.01$, eventually leads to overproduction and overpollution.

Initially, South responds to a stronger diffusion by cutting prices (though not all the way to the efficient). If knowledge spillovers are substantial, so are the price reductions which propel growth in the North. However, given its lack of care for the Southern environment, North overproduces to generate excess waste in the South (Table A.4). In the long-run, South increases resource prices sharply to compensate for the initial loss of welfare due to increased pollution and also to better exploit its monopoly power. Consequently, the long-run resource/knowledge mix is inefficiently low (see Fig. 3b). 

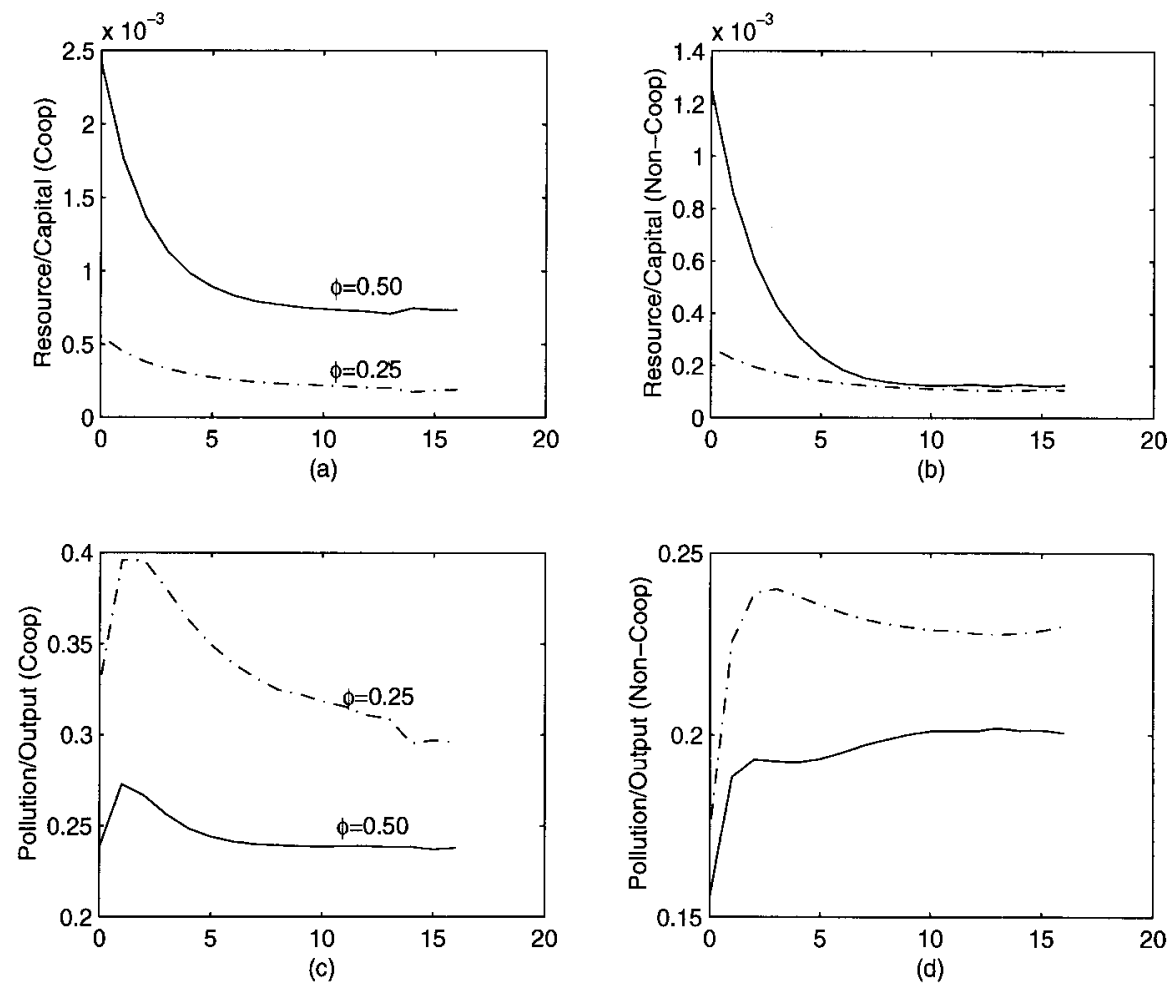

Fig. 3. Knowledge spillovers and trade

Now, assume that pollution becomes more persistent; that is, falls. World efficiency requires that output levels drop, necessitating a cut back in employment of resources and knowledge stock (Figs. $4 \mathrm{a}$ and $4 \mathrm{c}$ ). Moreover, efficient $R / K$ ratios rise as any additional waste created now lingers around longer. In contrast, noncooperative paths are marked by overproduction, low $R / K$ ratios and high monopoly prices (Figs. $4 \mathrm{~b}$ and $4 \mathrm{~d}$ and Tables A.2, A.5 and A.6). That is, as pollution becomes more persistent in the South, it further aggravates the distortions in the noncooperative North/South trade.

Finally, a Nash-Cournot resource duopoly in the South leads to overextraction and overpollution (Figs $5 \mathrm{a}$ and $5 \mathrm{~b}$ ). This time the main culprit is the policy externality between the two Southern producers in setting extraction paths. Since, neither internalizes the local damage from resource extraction in the other, they end up underestimating the true pollution costs (Table A.7). North takes advantage from cheap Southern resources by accelerating growth. The resulting transboundary waste further worsens the Southern welfare.

From a comparison of welfare under various sets of parameters in Table 1, we conclude that an uncoordinated resource extraction can cause a dramatic deterioration in the Southern well-being. In all instances, cooperation improves the global 

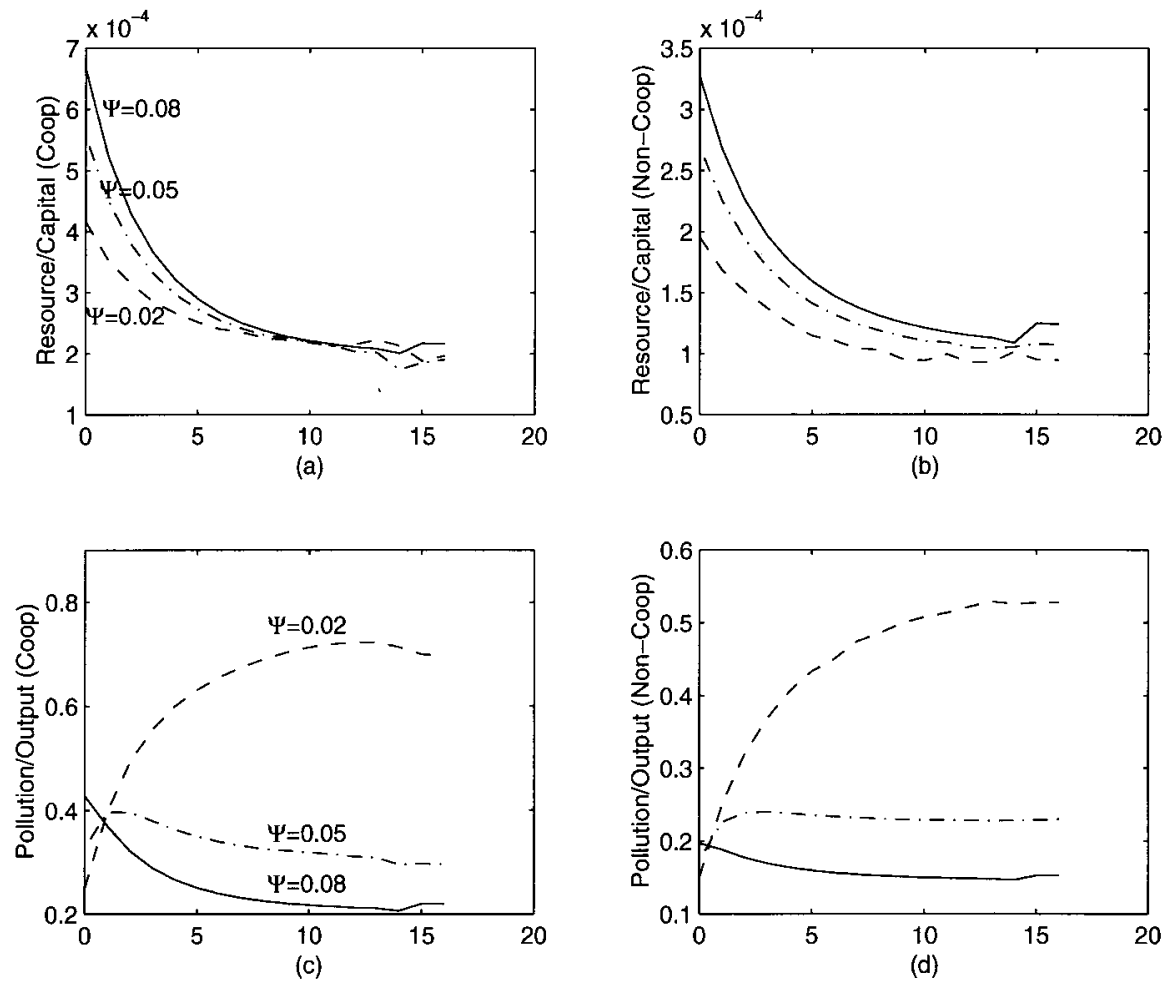

Fig. 4. Longevity of pollution and trade
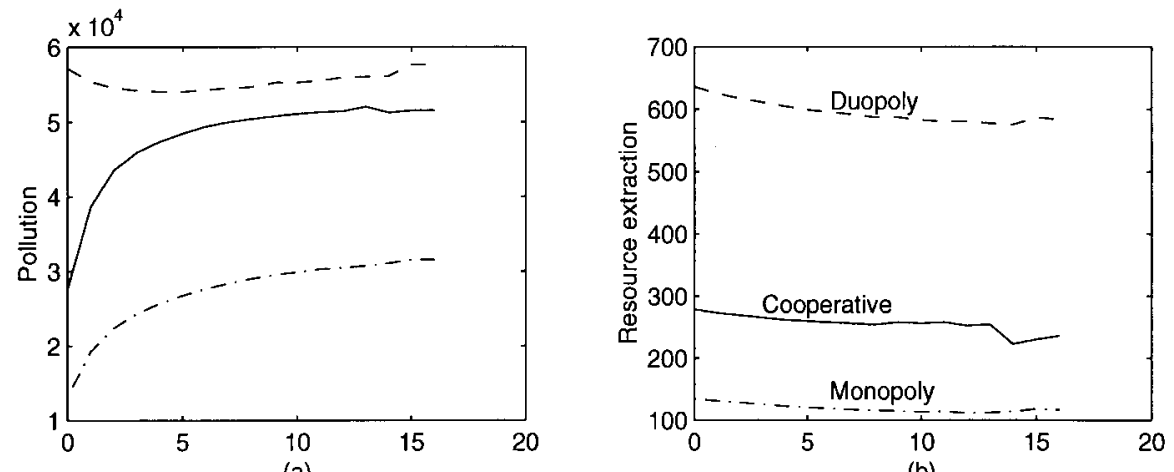

Fig. 5. Market structure and trade

welfare though, South has more to gain. Indeed, gains from cooperation are more substantial, more impervious the Southern pollution is. Absent cooperation, a simultaneous reduction in transboundary pollution and increased knowledge diffusion from North improves welfare in both regions. 
Table 1 Welfare comparisons

\begin{tabular}{lllllll}
\hline & & & \multicolumn{2}{l}{ Non-cooperative welfare } & \multicolumn{2}{l}{ Cooperative welfare } \\
$\boldsymbol{\phi}$ & $\boldsymbol{\varphi}$ & $\boldsymbol{\psi}$ & North & South & North & South \\
\hline 0.25 & 0 & 0.05 & -0.8138 & -1.03506 & -0.8693 & -0.92845 \\
0.25 & 0.01 & 0.05 & -0.8382 & -1.16094 & -0.7933 & -1.0571 \\
0.25 & 0.015 & 0.05 & -0.8506 & -1.22035 & -0.955 & -1.09946 \\
0.50 & 0.01 & 0.05 & -0.6426 & -1.00775 & -0.6151 & -0.88547 \\
0.25 & 0.01 & 0.02 & -0.8988 & -1.28051 & -0.9997 & -1.15847 \\
0.25 & 0.01 & 0.08 & -0.8031 & -1.09982 & -0.8922 & -0.99277 \\
\hline & & & Duopoly & North & South1 & South2 \\
\hline 0.25 & 0.01 & 0.05 & & -0.58606 & -1.3904 & -1.39022 \\
\hline
\end{tabular}

\section{Conclusion}

In a dynamic North/South trade model, we incorporate three specific concerns. First, when the Southern environment is exploited as a resource base, the damage can last a long time; second, Northern productive activities can generate transboundary pollution in the South; third, strategic rivalry amongst multiple producers in the South may also harm the Southern environment. For a given scenario, we construct a North/South trade game between multiple genetic algorithms which approximate the cooperative and noncooperative Nash equilibria of the game.

From a global perspective, Northern investment policies turn out to be inefficient because they discount both the benefits of knowledge spillovers and the costs of transboundary pollution to the South. A Southern resource monopoly, on the other hand, is inefficient because it ignores the adverse impact of such high prices on the Northern growth. To the extent competition in resource production erodes the monopoly rent, it will also enhance world efficiency. Rivalry in resource production, however, is found to be harmful when each competitive resource producer internalizes only the pollution in its own locale, leading to an overextraction at large. That is, a coordination amongst Southern producers gains a special significance when pollution is more local in nature. Furthermore, even in the absence of a global cooperation, substantial welfare gains accrue to both regions when productive activities pollute less, and create more knowledge spillovers.

The model can be extended to include pollution in the North as well. Though adding realism, the extra state variable associated with the Northern pollution stock will further complicate the couplings, and thereby, considerably increase the computational costs. Also, closed-loop Nash equilibria may be of interest, again for the sake of added realism. This would, however, require an altogether new genetic game algorithm which in itself is an open research area. 


\section{Acknowledgements}

Alemdar thanks colleagues at the University of Utah, especially Lance Girton, for the warm hospitality extended while on sabbatical leave. Özyildirim acknowledges the financial support from Turkish Science Foundation while visiting Harvard University.

\section{References}

Alemdar, N.M. and Özyildirim, S. (1998). 'A genetic game of trade, growth and externalities', Journal of Economic Dynamics and Control, 22, 811-32.

Başar, T. and Olsder, G.J. (1982). Dynamic Noncooperative Game Theory, Academic Press, New York, NY.

Chichilnisky, G. (1993). 'North, South trade and the dynamics of renewable resources', Structural Change and Economic Dynamics, 4, 219-48.

Chichilnisky, G. (1994). 'North, South trade and the global environment', American Economic Review, 84, 851-74.

Copeland, B.R. and Taylor, S.M. (1994). 'North-South trade and environment problems', Quarterly Journal of Economics, 109, 755-87.

Dasgupta, P. (1982). The Control of Resources, Basil Blackwell, Oxford.

Dockner, E.J. and Van Long, N. (1993). 'International pollution control: cooperative versus noncooperative strategies', Journal of Environmental Economics and Management, 24, 13-29.

Galor, O. (1986). 'Global dynamic inefficiency in the absence of international policy coordination: a North-South case', Journal of International Economics, 21, 137-49.

Goldberg, D.E. (1989). Genetic Algorithms in Search, Optimization, and Machine Learning, Addison-Wesley, Reading, MA.

Grefenstette, J.J. (1986). 'Optimization of control parameters for genetic algorithm', IEEE Transactions on Systems, Man and Cybernetics, 16, 122-28.

Grefenstette, J.J. (1990). A user's guide to GENESIS Version 5.0, manuscript.

Holland, J.H. (1975). Adaptation in Natural and Artificial Systems, The University of Michigan Press, Ann Arbor, MI.

Krishnakumar, K. and Goldberg, D.E. (1992). 'Control system optimization using genetic algorithm', Journal of Guidance, Control, and Dynamics, 15, 735-38.

Levhari, D. and Mirman, L.J. (1980). 'The great fishwar: an example using a dynamic Cournot-Nash solution', Bell Journal, 11, 322-34.

Mercenier, J. and Michel, P. (1994). 'Discrete-time finite horizon approximation of infinite horizon optimization problems with steady-state invariance', Econometrica, 62, 635-56.

Sachs, W., Loske, R., Linz, M., et al. (1998). Greening the North: A Post-Industrial Blueprint for Ecology and Equity, Zed Books Ltd., London.

Van Der Ploeg, F. and De Zeeuw, A.J. (1992). 'International aspects of pollution control', Environmental and Resource Economics, 2, 117-39.

Van Der Ploeg, F. and De Zeeuw, A.J. (1994). 'Investment in clean technology and transboundary pollution control', in Carlo Carraro (ed.), Trade, Innovation, Environment, Kluwer Academic Press, Dordrecht. 


\section{Appendix 1 North/South trade game in discrete-time}

The discrete-time approximation of the infinite horizon North/South trade model with steady state invariance is as follows:

North

$$
J^{N}=\max \sum_{h=0}^{H-1} \theta_{h}^{N} \Delta_{h} U^{N}\left(t_{h}\right)+\frac{\theta_{H-1}^{N}}{\rho_{N}} G^{N}\left(K\left(t_{H}\right)\right)
$$

subject to

$$
\begin{aligned}
& K\left(t_{h+1}\right)-K\left(t_{h}\right)=\Delta_{h}\left[Y\left(t_{h}\right)-p\left(t_{h}\right) R\left(t_{h}\right)-\delta K\left(t_{h}\right)-C^{N}\left(t_{h}\right)\right] \\
& K\left(t_{0}\right) \text { given }
\end{aligned}
$$

South

$$
J_{i}^{S}=\max \sum_{h=0}^{H-1} \theta_{h}^{S} \Delta_{h} U_{i}^{S}\left(t_{h}\right)+\frac{\theta_{H-1}^{S}}{\rho_{S}} G_{i}^{S}\left(K\left(t_{H}\right)\right), i=1,2
$$

subject to

$$
\begin{aligned}
K\left(t_{h+1}\right)-K\left(t_{h}\right) & =\Delta_{h}\left[Y\left(t_{h}\right)-p\left(t_{h}\right) R\left(t_{h}\right)-\delta K\left(t_{h}\right)-C^{N}\left(t_{h}\right)\right] \\
P_{i}\left(t_{h+1}\right)-P_{i}\left(t_{h}\right) & =\Delta_{h}\left[\frac{R_{i}\left(t_{h}\right)^{\gamma}}{\gamma K\left(t_{h}\right)^{\phi}}+\varphi_{i} Y\left(t_{h}\right)-\Psi P_{i}\left(t_{h}\right)\right] \\
C_{i}^{S}\left(t_{h}\right) & =p\left(t_{h}\right) R\left(t_{h}\right), K\left(t_{0}\right), P_{i}\left(t_{0}\right) \text { given }
\end{aligned}
$$

where $H$ is the assumed terminal time when the stationary state is reached, $\Delta_{h}$ is a scalar factor that converts the continuous flow into stock increments, $\Delta_{h}=t_{h+1}-t_{h}$ and $\theta_{h}^{j}$ is the sequence of discount factors of the region $j=N, S$ for which the stationary solution of the discrete-time problem is equivalent to the corresponding continuous-time problem. These sequences are given by the following recursions

$$
\theta_{h}^{N}=\frac{\theta_{h-1}^{N}}{1+\rho_{N} \Delta_{h}}, \theta_{0}^{N}>0 \quad \text { and } \quad \theta_{h}^{S}=\frac{\theta_{h-1}^{S}}{1+\rho_{S} \Delta_{h}}, \theta_{0}^{S}>0
$$

The functions $G^{j}($.$) denote the terminal values. { }^{8}$

\footnotetext{
${ }^{8}$ For details see Alemdar and Özyllırım (1998).
} 


\section{Appendix 2}

Table A.1 No transboundary waste, $\phi=0.25, \varphi=0.0, \psi=0.05$

\begin{tabular}{rrrrrrrrrr}
\hline & \multicolumn{4}{c}{ Noncooperative } & \multicolumn{5}{c}{ Cooperative } \\
$\mathbf{t}$ & \multicolumn{1}{c}{$\mathbf{K}_{\mathbf{t}}$} & $\mathbf{p}_{\mathbf{t}}$ & $\mathbf{R}_{\mathbf{t}}$ & \multicolumn{1}{c}{$\mathbf{Y}_{\mathbf{t}}$} & $\mathbf{K}_{\mathbf{t}}$ & $\mathbf{p}_{\mathbf{t}}$ & $\mathbf{R}_{\mathbf{t}}$ & $\mathbf{Y}_{\mathbf{t}}$ \\
\hline 0 & 500000.0 & 78.0 & 147.4 & 76636.6 & 500000.0 & 55.7 & 298.8 & 81324.9 \\
1 & 586999.0 & 89.6 & 145.6 & 86975.0 & 642717.5 & 67.2 & 297.4 & 99666.7 \\
2 & 671065.5 & 100.6 & 144.1 & 96656.0 & 795210.2 & 79.3 & 295.0 & 118252.0 \\
3 & 750244.4 & 110.7 & 143.0 & 105553.4 & 949657.9 & 90.0 & 294.7 & 136665.4 \\
4 & 823558.2 & 119.9 & 142.1 & 113616.1 & 1106060.6 & 100.7 & 294.0 & 154655.7 \\
5 & 891006.8 & 128.4 & 141.2 & 120883.0 & 1258553.3 & 111.0 & 293.1 & 171681.2 \\
6 & 950635.4 & 135.8 & 140.6 & 127229.9 & 1403225.8 & 120.1 & 292.8 & 187571.0 \\
7 & 1003421.3 & 142.4 & 139.9 & 132752.1 & 1540078.2 & 128.7 & 292.2 & 202242.4 \\
8 & 1049364.6 & 148.1 & 139.3 & 137506.3 & 1665200.4 & 135.8 & 292.4 & 215635.9 \\
9 & 1089442.8 & 152.9 & 138.9 & 141637.8 & 1782502.4 & 142.8 & 291.8 & 227862.3 \\
10 & 1123655.9 & 157.0 & 138.6 & 145140.2 & 1888074.3 & 149.3 & 290.8 & 238674.1 \\
11 & 1152981.4 & 160.6 & 138.4 & 148122.2 & 1981915.9 & 154.0 & 291.5 & 248462.1 \\
12 & 1178396.9 & 163.9 & 137.8 & 150649.6 & 2067937.4 & 159.4 & 289.4 & 257023.4 \\
13 & 1198924.7 & 166.3 & 137.8 & 152724.7 & 2144183.8 & 162.3 & 291.6 & 265078.8 \\
14 & 1216520.0 & 172.0 & 134.2 & 153912.2 & 2214565.0 & 168.8 & 290.3 & 271387.1 \\
15 & 1226295.2 & 157.8 & 149.7 & 157456.1 & 2261485.8 & 188.7 & 260.1 & 271393.6 \\
16 & 1226295.2 & 163.1 & 144.0 & 156544.3 & 2261485.8 & 183.0 & 274.3 & 272871.4 \\
\hline
\end{tabular}

Table A.2 Benchmark, $\phi=0.25, \varphi=0.0, \psi=0.05$

\begin{tabular}{|c|c|c|c|c|c|c|c|c|}
\hline \multirow[b]{2}{*}{$\mathbf{t}$} & \multicolumn{4}{|c|}{ Noncooperative } & \multicolumn{4}{|c|}{ Cooperative } \\
\hline & $\mathrm{K}_{\mathrm{t}}$ & $\mathbf{p}_{\mathrm{t}}$ & $\mathbf{R}_{\mathrm{t}}$ & $Y_{t}$ & $\mathbf{K}_{\mathbf{t}}$ & $p_{t}$ & $\mathbf{R}_{\mathrm{t}}$ & $Y_{t}$ \\
\hline 0 & 500000.0 & 84.4 & 134.4 & 75581.0 & 500000.0 & 63.5 & 278.3 & 84306.6 \\
\hline 1 & 582111.4 & 97.3 & 131.1 & 85047.0 & 606549.4 & 76.2 & 271.5 & 98029.9 \\
\hline 2 & 659530.8 & 109.6 & 128.2 & 93661.7 & 705278.6 & 86.9 & 267.6 & 110369.7 \\
\hline 3 & 730498.5 & 121.3 & 125.2 & 101284.5 & 795210.2 & 96.7 & 263.7 & 121213.0 \\
\hline 4 & 794428.2 & 132.0 & 122.7 & 107987.4 & 874389.1 & 105.5 & 260.8 & 130556.9 \\
\hline 5 & 850146.6 & 141.9 & 120.2 & 113648.4 & 941837.7 & 112.3 & 258.8 & 138397.1 \\
\hline 6 & 897654.0 & 149.7 & 118.7 & 118483.2 & 998533.7 & 118.2 & 257.8 & 144940.6 \\
\hline 7 & 938719.7 & 157.3 & 116.8 & 122498.2 & 1046432.1 & 124.0 & 254.9 & 150218.8 \\
\hline 8 & 973313.8 & 163.1 & 115.8 & 125943.8 & 1083578.6 & 128.9 & 252.9 & 154291.7 \\
\hline 9 & 1000879.8 & 168.4 & 114.5 & 128573.4 & 1111925.7 & 131.9 & 252.0 & 157421.2 \\
\hline 10 & 1023753.7 & 173.3 & 113.1 & 130670.4 & 1134409.1 & 134.8 & 251.0 & 159869.3 \\
\hline 11 & 1040176.0 & 174.5 & 113.9 & 132484.5 & 1152003.9 & 136.7 & 250.0 & 161755.4 \\
\hline 12 & 1057771.3 & 180.3 & 111.3 & 133809.6 & 1165689.1 & 138.7 & 249.0 & 163195.0 \\
\hline 13 & 1068328.4 & 180.9 & 111.9 & 134988.8 & 1178396.9 & 135.8 & 252.9 & 165001.4 \\
\hline 14 & 1077712.6 & 179.6 & 113.8 & 136276.6 & 1203812.3 & 144.6 & 240.3 & 166551.0 \\
\hline 15 & 1087683.3 & 175.8 & 117.8 & 137992.3 & 1211632.5 & 144.6 & 245.1 & 167922.0 \\
\hline 16 & 1087683.3 & 177.3 & 116.6 & 137782.1 & 1211632.5 & 144.6 & 246.1 & 168022.1 \\
\hline
\end{tabular}




\section{KNOWLEDGE SPILLOVERS}

Table A.3 High transboundary waste, $\phi=0.25, \varphi=0.015, \psi=0.05$

\begin{tabular}{|c|c|c|c|c|c|c|c|c|}
\hline \multirow[b]{2}{*}{$\mathbf{t}$} & \multicolumn{4}{|c|}{ Noncooperative } & \multicolumn{4}{|c|}{ Cooperative } \\
\hline & $\mathrm{K}_{\mathrm{t}}$ & $p_{t}$ & $\mathbf{R}_{\mathrm{t}}$ & $Y_{t}$ & $\mathrm{~K}_{\mathrm{t}}$ & $\mathbf{p}_{\mathrm{t}}$ & $\mathbf{R}_{\mathbf{t}}$ & $Y_{t}$ \\
\hline 0 & 500000.0 & 87.2 & 129.3 & 75151.2 & 500000.0 & 67.8 & 268.3 & 78556.5 \\
\hline 1 & 580058.7 & 101.3 & 124.6 & 84155.1 & 588954.1 & 78.9 & 262.6 & 89217.1 \\
\hline 2 & 654643.2 & 114.6 & 120.8 & 92279.0 & 669110.5 & 89.0 & 258.0 & 98500.5 \\
\hline 3 & 721700.9 & 127.3 & 117.0 & 99295.2 & 738514.2 & 97.9 & 254.0 & 106282.1 \\
\hline 4 & 780547.4 & 138.5 & 114.0 & 105310.2 & 796187.7 & 105.3 & 250.7 & 112613.2 \\
\hline 5 & 830498.5 & 148.9 & 111.1 & 110234.4 & 843108.5 & 111.3 & 248.4 & 117703.2 \\
\hline 6 & 872238.5 & 157.3 & 109.0 & 114322.4 & 881231.7 & 116.1 & 246.6 & 121788.9 \\
\hline 7 & 907135.9 & 164.9 & 107.0 & 117635.6 & 911534.7 & 120.0 & 245.2 & 124995.6 \\
\hline 8 & 935190.6 & 171.0 & 105.5 & 120283.2 & 934995.1 & 123.0 & 244.0 & 127469.6 \\
\hline 9 & 957771.3 & 175.6 & 104.6 & 122443.0 & 953567.9 & 125.4 & 242.9 & 129406.5 \\
\hline 10 & 975562.1 & 182.3 & 101.8 & 123763.6 & 968230.7 & 125.9 & 244.6 & 131175.8 \\
\hline 11 & 989247.3 & 186.4 & 100.5 & 124905.1 & 982893.5 & 129.3 & 241.3 & 132430.9 \\
\hline 12 & 996774.2 & 186.5 & 101.2 & 125785.4 & 991691.1 & 129.6 & 241.2 & 133478.6 \\
\hline 13 & 1005669.6 & 184.0 & 103.6 & 127139.6 & 1001466.3 & 130.9 & 241.0 & 134479.6 \\
\hline 14 & 1016617.8 & 188.9 & 101.6 & 127858.5 & 1008308.9 & 131.7 & 242.3 & 135209.1 \\
\hline 15 & 1020723.4 & 188.6 & 102.1 & 128372.6 & 1011241.4 & 134.8 & 235.5 & 135013.5 \\
\hline 16 & 1020723.4 & 186.9 & 103.2 & 128585.1 & 1011241.4 & 133.4 & 239.8 & 135277.8 \\
\hline
\end{tabular}

Table A.4 High knowledge spillovers, $\phi=0.50, \varphi=0.01, \psi=0.05$

\begin{tabular}{|c|c|c|c|c|c|c|c|c|}
\hline \multirow[b]{2}{*}{$\mathbf{t}$} & \multicolumn{4}{|c|}{ Noncooperative } & \multicolumn{4}{|c|}{ Cooperative } \\
\hline & $\mathrm{K}_{\mathrm{t}}$ & $p_{t}$ & $\mathbf{R}_{\mathrm{t}}$ & $Y_{t}$ & $K_{t}$ & $p_{t}$ & $\mathbf{R}_{\mathbf{t}}$ & $Y_{t}$ \\
\hline 0 & 500000.0 & 22.6 & 631.6 & 95333.9 & 500000.0 & 20.7 & 1211.3 & 105115.2 \\
\hline 1 & 704398.8 & 31.0 & 603.6 & 124557.0 & 677908.1 & 27.1 & 1196.7 & 133854.7 \\
\hline 2 & 937047.9 & 41.5 & 559.1 & 154713.8 & 853861.2 & 33.7 & 1171.8 & 160485.7 \\
\hline 3 & 1184653.0 & 54.7 & 503.8 & 183743.6 & 1012219.0 & 39.8 & 1148.3 & 183328.3 \\
\hline 4 & 1425610.9 & 70.7 & 443.7 & 209057.1 & 1143206.3 & 45.2 & 1124.9 & 201449.3 \\
\hline 5 & 1639980.5 & 89.4 & 383.9 & 228822.7 & 1241935.5 & 49.4 & 1107.3 & 214743.0 \\
\hline 6 & 1809481.9 & 109.6 & 331.4 & 242157.4 & 1314271.8 & 52.6 & 1092.6 & 224243.6 \\
\hline 7 & 1924144.7 & 127.9 & 292.7 & 249661.8 & 1364125.1 & 55.0 & 1080.9 & 230649.6 \\
\hline 8 & 1992277.6 & 139.3 & 273.7 & 254133.5 & 1396383.2 & 56.4 & 1076.5 & 234859.2 \\
\hline 9 & 2027175.0 & 147.3 & 260.4 & 255772.6 & 1416911.0 & 57.9 & 1064.8 & 237227.3 \\
\hline 10 & 2042131.0 & 152.8 & 251.3 & 255914.4 & 1424731.2 & 58.9 & 1054.5 & 237928.5 \\
\hline 11 & 2050439.9 & 150.8 & 256.2 & 257486.3 & 1421798.6 & 59.6 & 1041.4 & 237088.6 \\
\hline 12 & 2058748.8 & 148.5 & 261.7 & 259152.9 & 140909.9 & 60.3 & 1020.8 & 234690.4 \\
\hline 13 & 2062072.3 & 155.0 & 249.3 & 257602.1 & 1394428.2 & 61.0 & 988.6 & 231617.2 \\
\hline 14 & 2060410.6 & 147.6 & 263.8 & 259635.4 & 1388563.1 & 57.4 & 1038.4 & 232546.1 \\
\hline 15 & 2082013.7 & 154.1 & 253.3 & 260220.4 & 1414956.0 & 59.1 & 1039.9 & 236125.5 \\
\hline 16 & 2082013.7 & 150.8 & 259.9 & 261216.3 & 1414956.0 & 59.1 & 1041.4 & 236175.4 \\
\hline
\end{tabular}


Table A.5 More persistent pollution, $\phi=0.25, \varphi=0.01, \psi=0.02$

\begin{tabular}{|c|c|c|c|c|c|c|c|c|}
\hline \multirow[b]{2}{*}{$\mathbf{t}$} & \multicolumn{4}{|c|}{ Noncooperative } & \multicolumn{4}{|c|}{ Cooperative } \\
\hline & $\mathrm{K}_{\mathrm{t}}$ & $p_{t}$ & $\mathbf{R}_{\mathrm{t}}$ & $Y_{t}$ & $K_{t}$ & $p_{t}$ & $\mathbf{R}_{\mathbf{t}}$ & $Y_{t}$ \\
\hline 0 & 500000.0 & 110.7 & 97.7 & 72048.8 & 500000.0 & 83.1 & 208.1 & 75790.5 \\
\hline 1 & 561583.6 & 124.8 & 94.6 & 78691.5 & 572140.8 & 94.8 & 202.3 & 84059.4 \\
\hline 2 & 616129.0 & 135.8 & 93.5 & 84591.3 & 634604.1 & 104.6 & 200.3 & 91079.6 \\
\hline 3 & 664516.1 & 146.8 & 91.5 & 89586.9 & 688269.8 & 114.3 & 196.4 & 96773.7 \\
\hline 4 & 705865.1 & 158.8 & 88.4 & 93521.9 & 729618.8 & 120.2 & 194.5 & 101337.9 \\
\hline 5 & 741055.7 & 170.5 & 85.1 & 96680.0 & 764809.4 & 126.1 & 192.5 & 105045.2 \\
\hline 6 & 779765.4 & 175.2 & 86.4 & 100941.2 & 792082.1 & 131.9 & 190.5 & 107699.7 \\
\hline 7 & 791202.3 & 184.1 & 82.7 & 101441.6 & 810557.2 & 133.9 & 190.5 & 109777.2 \\
\hline 8 & 811437.0 & 185.5 & 83.9 & 103742.0 & 825513.2 & 139.7 & 186.6 & 110841.1 \\
\hline 9 & 825513.2 & 197.7 & 79.1 & 104256.5 & 831671.6 & 141.7 & 184.7 & 111346.0 \\
\hline 10 & 835190.6 & 200.1 & 78.9 & 105187.2 & 835190.6 & 141.7 & 184.7 & 111789.3 \\
\hline 11 & 840469.2 & 190.9 & 83.8 & 106690.6 & 838709.7 & 145.6 & 178.8 & 111695.0 \\
\hline 12 & 850146.6 & 202.9 & 78.9 & 106695.7 & 839589.4 & 143.6 & 180.8 & 112072.2 \\
\hline 13 & 847507.3 & 202.4 & 78.9 & 106427.4 & 846627.6 & 137.8 & 188.6 & 113789.8 \\
\hline 14 & 858064.5 & 187.9 & 87.1 & 109101.1 & 866862.2 & 135.8 & 184.7 & 116641.3 \\
\hline 15 & 877419.4 & 197.9 & 83.7 & 110392.0 & 909090.9 & 157.3 & 171.0 & 118859.9 \\
\hline 16 & 877419.4 & 198.9 & 83.2 & 110299.9 & 909090.9 & 153.4 & 178.8 & 119388.7 \\
\hline
\end{tabular}

Table A.6 Less persistent pollution, $\phi=0.25, \varphi=0.01, \psi=0.08$

\begin{tabular}{rrrrrrrrr}
\hline & \multicolumn{4}{c}{ Noncooperative } & \multicolumn{5}{c}{ Cooperative } \\
$\mathbf{t}$ & \multicolumn{1}{c}{$\mathbf{K}_{\mathbf{t}}$} & \multicolumn{1}{c}{$\mathbf{p}_{\mathbf{t}}$} & $\mathbf{R}_{\mathbf{t}}$ & $\mathbf{Y}_{\mathbf{t}}$ & $\mathbf{K}_{\mathbf{t}}$ & $\mathbf{p}_{\mathbf{t}}$ & $\mathbf{R}_{\mathbf{t}}$ & $\mathbf{Y}_{\mathbf{t}}$ \\
\hline 0 & 500000.0 & 71.6 & 163.1 & 77813.0 & 500000.0 & 54.1 & 333.7 & 81747.5 \\
1 & 594623.7 & 83.9 & 159.3 & 89068.5 & 626099.7 & 65.4 & 328.3 & 97696.2 \\
2 & 686901.3 & 96.0 & 155.6 & 99610.8 & 750733.1 & 76.4 & 323.2 & 112763.8 \\
3 & 772922.8 & 107.5 & 152.3 & 109121.8 & 869501.5 & 86.8 & 318.7 & 126593.4 \\
4 & 851124.1 & 117.9 & 149.6 & 117549.4 & 978005.9 & 96.5 & 314.4 & 138796.1 \\
5 & 920723.4 & 127.4 & 147.0 & 124850.5 & 1073313.8 & 104.8 & 311.0 & 149286.2 \\
6 & 981720.4 & 135.9 & 144.7 & 131116.8 & 1155425.2 & 112.2 & 308.1 & 158114.4 \\
7 & 1034115.3 & 143.1 & 143.0 & 136446.9 & 1224340.2 & 118.5 & 305.8 & 165371.4 \\
8 & 1078690.1 & 149.4 & 141.5 & 140899.3 & 1280058.7 & 123.2 & 304.2 & 171267.3 \\
9 & 1116226.8 & 154.7 & 140.2 & 144620.5 & 1326979.5 & 127.6 & 302.4 & 176075.8 \\
10 & 1147507.3 & 159.1 & 139.3 & 147699.1 & 1363636.4 & 130.5 & 301.7 & 179926.9 \\
11 & 1173313.8 & 162.9 & 138.3 & 150194.4 & 1394428.2 & 133.1 & 300.9 & 183100.1 \\
12 & 1193646.1 & 166.0 & 137.5 & 152139.2 & 1419354.8 & 135.6 & 299.7 & 185570.6 \\
13 & 1210850.4 & 168.3 & 137.1 & 153820.7 & 1438416.4 & 137.1 & 299.1 & 187559.0 \\
14 & 1224144.7 & 173.8 & 133.4 & 154542.1 & 1454545.5 & 140.2 & 291.7 & 188796.3 \\
15 & 1228836.8 & 154.7 & 153.5 & 158312.9 & 1470674.5 & 135.2 & 319.5 & 191989.0 \\
16 & 1228836.8 & 155.3 & 152.8 & 158207.2 & 1470674.5 & 135.5 & 318.5 & 191915.6 \\
\hline
\end{tabular}




\section{KNOWLEDGE SPILLOVERS}

Table A.7 Duopoly in the South

\begin{tabular}{rrrrrrrr}
\hline $\mathbf{t}$ & $\mathbf{K}_{\mathbf{t}}$ & $\mathbf{p}_{\mathbf{t}}$ & $\mathbf{R}_{\mathbf{1 t}}$ & $\mathbf{R}_{\mathbf{2 t}}$ & $\mathbf{R}_{\mathbf{t}} / \mathbf{K}_{\mathbf{t}}$ & $\mathbf{P}_{\mathbf{1 t}}$ & $\mathbf{P}_{\mathbf{2 t}}$ \\
\hline 0 & 500000.0 & 22.5 & 318.1 & 318.2 & 0.00127 & 28552.8 & 28576.0 \\
1 & 609677.4 & 26.8 & 312.5 & 312.9 & 0.00103 & 27666.1 & 27716.7 \\
2 & 720430.1 & 30.9 & 309.0 & 308.7 & 0.00086 & 27296.7 & 27262.5 \\
3 & 827957.0 & 34.8 & 305.4 & 305.9 & 0.00074 & 27076.7 & 27135.5 \\
4 & 931182.8 & 38.6 & 303.0 & 302.2 & 0.00065 & 27074.5 & 26986.5 \\
5 & 1027957.0 & 42.1 & 299.5 & 299.8 & 0.00058 & 27005.6 & 27036.0 \\
6 & 1116129.0 & 45.2 & 298.0 & 297.6 & 0.00053 & 27172.9 & 27131.5 \\
7 & 1195698.9 & 48.1 & 295.6 & 296.2 & 0.00050 & 27231.8 & 27295.3 \\
8 & 1267741.9 & 50.7 & 294.0 & 293.6 & 0.00046 & 27369.9 & 27324.7 \\
9 & 1332258.1 & 52.7 & 292.7 & 294.7 & 0.00044 & 27521.6 & 27728.0 \\
10 & 1390322.6 & 54.9 & 291.5 & 291.4 & 0.00042 & 27650.3 & 27644.8 \\
11 & 1438709.7 & 56.6 & 289.6 & 291.2 & 0.00040 & 27682.9 & 27850.7 \\
12 & 1482795.7 & 58.0 & 289.2 & 291.5 & 0.00039 & 27857.3 & 28082.7 \\
13 & 1522580.6 & 59.5 & 290.1 & 287.8 & 0.00038 & 28131.6 & 27903.4 \\
14 & 1556989.2 & 60.8 & 288.8 & 286.7 & 0.00037 & 28158.7 & 27959.0 \\
15 & 1591397.8 & 60.8 & 293.3 & 293.7 & 0.00037 & 28814.6 & 28851.9 \\
16 & 1591397.8 & 61.1 & 292.3 & 292.0 & 0.00037 & 28814.6 & 28851.9 \\
\hline
\end{tabular}

